\title{
Short communication: Urea hydrolysis in dairy cattle manure under different temperature, urea, and $\mathrm{pH}$ conditions
}

\author{
L. E. Moraes, ${ }^{* 1}$ S. A. Burgos, ${ }^{* 2}$ E. J. DePeters, ${ }^{*}$ R. Zhang, $†$ and J. G. Fadel ${ }^{\star 3}$ \\ *Department of Animal Science, and \\ †Department of Biological and Agricultural Engineering, University of California, Davis 95616
}

\begin{abstract}
The objective of the study was to quantify the rate of urea hydrolysis in dairy cattle manure under different initial urea concentration, temperature, and $\mathrm{pH}$ conditions. In particular, by varying all 3 factors simultaneously, the interactions between them could also be determined. Fresh feces and artificial urine solutions were combined into a slurry to characterize the rate of urea hydrolysis under 2 temperatures $\left(15^{\circ} \mathrm{C}\right.$ and $\left.35^{\circ} \mathrm{C}\right)$, 3 urea concentrations in urine solutions $(500,1,000$, and $1,500 \mathrm{mg}$ of urea- $\mathrm{N} / \mathrm{dL})$, and $3 \mathrm{pH}$ levels $(6,7$, and 8 ). Urea $\mathrm{N}$ concentration in slurry was analyzed at $0.0167,1,2,4,6,8,12,16,20$, and $24 \mathrm{~h}$ after initial mixing. A nonlinear mixed effects model was used to determine the effects of urea concentration, $\mathrm{pH}$, and temperature treatments on the exponential rate of urea hydrolysis and to predict the hydrolysis rate for each treatment combination. We detected a significant interaction between $\mathrm{pH}$ and initial urea level. Increasing urea concentration from 1,000 to $1,500 \mathrm{mg}$ of urea-N/ $\mathrm{dL}$ decreased the rate of urea hydrolysis across all $\mathrm{pH}$ levels. Across all $\mathrm{pH}$ and initial urea levels, the rate of urea hydrolysis increased with temperature, but the effect of $\mathrm{pH}$ was only observed for $\mathrm{pH} 6$ versus $\mathrm{pH} 8$ at the intermediate initial urea concentration. The fast rates of urea hydrolysis indicate that urea was almost completely hydrolyzed within a few hours of urine mixing with feces. The estimated urea hydrolysis rates from this study are likely maximum rates because of the thorough mixing before each sampling. Although considerable mixing of feces and urine occurs on the barn floor of commercial dairy operations from cattle walking through the manure, such mixing may be not as quick and thorough as in this study. Consequently,
\end{abstract}

Received August 26, 2016.

Accepted November 11, 2016.

${ }^{1}$ Current address: Department of Animal Sciences, The Ohio State University, Columbus 43210.

${ }^{2}$ Current address: Department of Animal Science, McGill University, Sainte-Anne-de-Bellevue, QC, H9X 3V9, Canada.

${ }^{3}$ Corresponding author: jgfadel@ucdavis.edu the urea hydrolysis rates from this study indicate the maximum loss of urea and should be accounted for in management aimed at mitigating ammonia emissions from dairy cattle manure under similar urea concentration, $\mathrm{pH}$, and temperature conditions reported in this experiment.

Key words: urea hydrolysis, temperature, urea concentration, $\mathrm{pH}$

\section{Short Communication}

Ammonia emissions from manure in livestock operations are related to respiratory problems in humans and animals and may contribute to additional air quality and health issues through secondary particulate formation (McCubbin et al., 2002; Behera et al., 2013). Quantifying urea hydrolysis under different conditions is the first step to understanding the factors affecting ammonia production and to identifying potential ammonia mitigation strategies because most of the ammonia in the manure is generated from urea hydrolysis, especially in the short term (Monteny and Erisman, 1998; Dai and Karring, 2014). A previous study from our laboratory predicted ammonia emissions from dairy manure under different $\mathrm{N}$ feeding conditions (Burgos et al., 2010), but that experiment was not designed to evaluate the effects of different urea, $\mathrm{pH}$, or temperature conditions. Previous studies have evaluated urease activity in dairy cattle manure under different temperature, urea concentration, or $\mathrm{pH}$ conditions but have not evaluated all these factors simultaneously (Muck, 1982; Dai and Karring, 2014). Elzing and Monteny (1997) found that most of the urea was converted to ammonia during the first few hours when urine was applied on fouled slatted floors at $10^{\circ} \mathrm{C}$.

The primary pathway for urea hydrolysis in manure begins with the conversion of urinary urea to $\mathrm{NH}_{3}$ and $\mathrm{CO}_{2}$, which is catalyzed by the activity of urease present in feces. Once generated, ammonia in aqueous solution is present as both $\mathrm{NH}_{4}{ }^{+}$and $\mathrm{NH}_{3}$, which are coupled in equilibrium by a dissociation reaction. The equilibrium between the volatile $\mathrm{NH}_{3}$ and nonvolatile $\mathrm{NH}_{4}{ }^{+}$is 
temperature and $\mathrm{pH}$ dependent. The volatilization of ammonia occurs via convective mass transfer from the boundary layer of the manure slurry to the air above the surface (Monteny and Erisman, 1998). The mass transfer coefficient is dependent on air velocity, liquid temperature, and air temperature (Arogo et al., 1999).

The optimum $\mathrm{pH}$ for maximum urease activity was reported to be from 6.8 to 8 (Muck, 1982; Dai and Karring, 2014). However, none of these studies examined the effects of temperature, urea concentration, $\mathrm{pH}$, and their interactions within the same experiment. The objective of this study was to determine urea hydrolysis rates over time under different temperature, initial urea concentration, and $\mathrm{pH}$ conditions.

Fresh feces (3.1\% N DM) and artificial urine solutions (urea in distilled deionized water) were combined into a slurry to characterize the rate of urea hydrolysis under 2 temperature conditions $\left(15^{\circ} \mathrm{C}\right.$ and $\left.35^{\circ} \mathrm{C}\right), 3$ urea concentrations in urine solutions $(500,1,000$, and $1,500 \mathrm{mg}$ of urea-N/dL), and $3 \mathrm{pH}$ levels (6, 7, and 8). The choice of temperature, urea concentrations, and $\mathrm{pH}$ levels was based on literature values to include relevant treatment levels (Muck, 1982; Burgos et al., 2010; Dai and Karring, 2014). Artificial urine (described below) was used so that initial urea- $\mathrm{N}$ concentrations could be created to precisely equal the treatment levels. The feces were obtained from 4 lactating Holstein cows, housed in a tiestall and fitted with indwelling Foley catheters during the last day of the last experimental period in a study described previously (Burgos et al., 2007). The fresh feces used in this experiment were less than $24 \mathrm{~h}$ old. The catheters prevented any mixing of feces and urine. A total of $17.5 \mathrm{~kg}$ of feces was collected from each cow, resulting in $70 \mathrm{~kg}$ of feces, which were thoroughly mixed with a Hobart mixer (Troy, OH). Then, the feces were split into 3 equal $23.3-\mathrm{kg}$ batches. To each feces batch, $21.1 \mathrm{~kg}$ of distilled deionized water was added to a final weight of $44.4 \mathrm{~kg}$, such that the resulting slurry contained about $47 \%$ added water, which is similar to the proportion of urine to manure found in a previous study (Burgos et al., 2010). A portion $(37 \mathrm{~kg}$ ) of each $44.4-\mathrm{kg}$ batch of slurry was placed into 3 separate containers and the $\mathrm{pH}$ of each $37-\mathrm{kg}$ slurry sample adjusted to 6,7 , or 8 using $1 M \mathrm{NaOH}$ and $1 M \mathrm{HCl}$. Then, the manure from each $\mathrm{pH}$ container was transferred into 18 identical clean 2-L plastic bottles, with each bottle containing $1.75 \mathrm{~kg}$ of manure slurry. Of these bottles, 9 were placed in a $15^{\circ} \mathrm{C}$ room and 9 were placed in a $35^{\circ} \mathrm{C}$ room and allowed to come to thermal equilibrium. This was repeated for each $\mathrm{pH}$ container such that there were 27 bottles in each temperature-controlled room. Separately, eighteen 87.5-mL solutions of 500, 1,000, or $1,500 \mathrm{mg}$ of urea- $\mathrm{N} / \mathrm{dL}$ in deionized distilled water (54 solutions in total) were prepared to be added into the bottles in each room. The concentration of urea in the artificial urine spans the concentrations of urinary urea-N measured in our previous study (Burgos et al., 2010). For each urea concentration, nine $87.5-\mathrm{mL}$ solutions were placed in each temperature-controlled room and allowed to come to thermal equilibrium.

The experiment was initiated by adding $87.5 \mathrm{~mL}$ of each urea concentration to the bottles (and immediately mixed) such that each treatment combination had 3 replicates. The final concentrations for the urea treatments were 250,500 , or $750 \mathrm{mg}$ of urea-N/dL in the slurry, which were considered to be the initial urea concentrations. Bottle contents were mixed before sample collection and a 10-mL sample drawn after 0.0167, 1, $2,4,6,8,12,16,20$, and $24 \mathrm{~h}$. Each 10-mL sample was immediately added to a $50-\mathrm{mL}$ tube containing $0.1 \mathrm{~mL}$ of $18 \mathrm{M} \mathrm{H}_{2} \mathrm{SO}_{4}$ and then mixed thoroughly to prevent further urea hydrolysis. The start of the incubations for each treatment condition was staggered by $5 \mathrm{~min}$ to ensure that all the bottles had the same sampling schedule. Acidified slurry samples were analyzed for urea $\mathrm{N}$ concentration with a diacetyl-monoxime method (Marsh et al., 1957) using a Technicon autoanalyzer (Technicon Instruments Corp., Tarrytown, NY). Total ammoniacal N (TAN) in the slurry was measured at 24 $\mathrm{h}$ and analyzed using automated colorimetry (Noel and Hambleton, 1976). The initial $\mathrm{pH}$ and the slurry $\mathrm{pH}$ at $24 \mathrm{~h}$ were measured using a Thermo Orion Perphect pH meter (model no. 320, Thermo Orion, Beverly, MA) with an Accumet $\mathrm{pH}$ combination electrode (Fisher Scientific, Pittsburgh, PA). Four observations were removed from the data set because the urea concentration at $0.0167 \mathrm{~h}$ was $25 \%$ higher than that at time $0 \mathrm{~h}$. These urea concentrations were considered sampling errors due to inadequate mixing because urea concentration should decrease with time as a result of hydrolysis.

A nonlinear mixed-effects model was used to describe the effects of temperature, initial urea concentration, and $\mathrm{pH}$ on urea hydrolysis over time. In particular, an exponential function was used to model the data with respect to time:

$$
y_{i j}=\phi_{1, i} \exp \left(-\phi_{2, i} t_{i m e_{i j}}\right)+\varepsilon_{i j}
$$

where $y_{i j}$ is the urea concentration in the $i$ th bottle $(i=$ $1, \ldots, 54)$ at sampling time $j\left(j=1, \ldots, n_{i}\right)$, time $e_{i j}$ is the corresponding sampling time, and $\varepsilon_{i j}$ is the error. Because of initial indication of heteroscedasticity for the errors, they were assumed to be normally distributed with mean zero and $\operatorname{Var}\left(\varepsilon_{i j}\right)=\sigma^{2} \exp \left(2 \delta_{i} t i m e_{i j}\right)$. In this framework, the variance is an exponential function of time and the parameter $\delta_{i}$ is unrestricted, allowing the variance to increase or decrease with time 
(Pinheiro and Bates, 2000). The indexing $i$ on $\delta_{i}$ allows it to depend on a factor describing the experimental treatments. We used the urea treatment to accommodate further errors' heterogeneities across initial urea levels: $\delta_{i}=\varphi_{1} z_{1, i}+\varphi_{2} z_{2, i}+\varphi_{3} z_{3, i}$, where $z_{1, i}, z_{2, i}$, and $z_{3, i}$ are binary dummy variables relating $\delta_{i}$ to the urea-N level treatment $(500,1,000$, or $1,500 \mathrm{mg}$ of urea-N/dL); and $\varphi_{1}, \varphi_{2}$, and $\varphi_{3}$ are the parameters of the variance function describing changes in the errors variance with time for the 3 initial urea level treatments.

The parameters to be estimated in Eq. [1] are $\phi_{1, i}$ and $\phi_{2, i}$, which represent the estimated urea concentration at time zero and the exponential rate of decay or urea hydrolysis rate. In the nonlinear mixed effects framework, treatment effects are incorporated directly into the model parameters:

$$
\left[\begin{array}{l}
\phi_{1, i} \\
\phi_{2, i}
\end{array}\right]=\left[\begin{array}{c}
\alpha_{1} x_{1, i}+\alpha_{2} x_{2, i}+\cdots+\alpha_{17} x_{17, i}+\alpha_{18} x_{18, i} \\
\beta_{1} x_{1, i}+\beta_{2} x_{2, i}+\cdots+\beta_{17} x_{17, i}+\beta_{18} x_{18, i}
\end{array}\right]+\left[\begin{array}{c}
b_{1, i} \\
b_{2, i}
\end{array}\right],
$$

where $x_{1, i}, \ldots, x_{18, i}$ are binary dummy variables representing the effects of the temperature $\left(15^{\circ} \mathrm{C}\right.$ and $\left.35^{\circ} \mathrm{C}\right), \mathrm{pH}(6,7$ and 8$)$, and initial urea concentration in urea solution $(500,1,000$, or $1,500 \mathrm{mg}$ of urea-N/dL) treatments on the model parameters. Eighteen binary dummy variables were needed to represent main effects, 2 -way and 3-way interactions. In this notation, the fixed effects determining treatment effects on the intercept and rate parameter are given by $\left(\alpha_{1}, \ldots, \alpha_{18}\right)$ and $\left(\beta_{1}\right.$, $\left.\ldots, \beta_{18}\right)$, respectively. Multiple records were collected longitudinally on each bottle; therefore, observations originated from the same bottle are not independent and an intrinsic contribution of the manure sample in each bottle for the total variation in the data is present. Specific levels for these bottle effects are, however, not of interest in this study, and the bottle effects $\left(b_{1, i}\right.$ and $\left.b_{2, i}\right)$ were therefore assumed to be random. In short, the random effects represent shifts in the parameters of the exponential model for each bottle (from the average parameters in its treatment group), which are, on average, zero. It was assumed that observations corresponding to different bottles were independent and that the errors $\varepsilon_{i j}$ were independent of the $b_{1, i}$ and $b_{2, i}$. Further, random effects were assumed to be independent and distributed as

$$
\left[\begin{array}{l}
b_{1, i} \\
b_{2, i}
\end{array}\right] \sim N\left(\left[\begin{array}{l}
0 \\
0
\end{array}\right],\left[\begin{array}{cc}
\sigma_{1}^{2} & \sigma_{12} \\
\sigma_{12} & \sigma_{2}^{2}
\end{array}\right]\right),
$$

where $\sigma_{1}^{2}, \sigma_{2}^{2}$, and $\sigma_{12}$ are the variance components associated with the bottles' random effects. The model was fitted using maximum likelihood in the nlme package in R (Pinheiro et al., 2016). Hypothesis testing for fixed effects used conditional F-tests based on the conditional estimate of the variance (Pinheiro and Bates, 2000). The exponential decay rates were predicted using the fixed effects of the full model described in Eq. [2]. Subsequently, a stepwise approach was used to reduce the model and determine appropriate multiple comparisons for the urea hydrolysis rate parameters. First, the significance of the 3-way and 2-way interactions was sequentially examined. If the 3 -way interaction was not different from zero (at the given 0.05 statistical significance level), it was removed from the model and a model containing only 2-way interactions was then fitted. Next, if 2-way interaction terms were not significantly different than zero, the main effects were compared directly. If any interaction term was significant for 2 factors, one factor was compared within each level of the other factor. Multiple comparisons were conducted with the multcomp package in $\mathrm{R}$ (Hothorn et al., 2008) for which the single-step method was used to adjust the significance level and construct 95\% family-wise confidence intervals. A similar model reduction approach was used to describe the effects of temperature, urea concentration and $\mathrm{pH}$ on final TAN or final $\mathrm{pH}$ except a linear model was used and TAN was transformed as a natural $\log$ to ensure normally distributed and homoscedastic residuals.

Table 1 shows the estimate of the individual rates $\left(\phi_{2}\right)$ of the full model Eq. [2] before model reduction. The estimates of the rates of hydrolysis, as well as the associated standard errors, are given for the 18 possible combinations of temperature, urea, and $\mathrm{pH}$. The fast rates of urea hydrolysis are particularly high, especially at the higher temperature, and even some rates at $15^{\circ} \mathrm{C}$ were relatively fast. These results show that the fast rates of urea hydrolysis require careful experimental designs to capture the urea hydrolysis and subsequent changes in $\mathrm{NH}_{3}$ and $\mathrm{NH}_{4}{ }^{+}$concentrations in the slurry and ammonia emitted. Careful mass balance experiments may be able to characterize this reaction more precisely.

Sequential model reductions resulted in a model with the rate parameter with main effect of initial urea concentration, $\mathrm{pH}$, and temperature as well as a 2-way interaction of initial urea level and $\mathrm{pH}$ treatments. Figure 1 shows that the reduced model fit was overall very good across all treatment combinations and replicates. Figure 2 shows the differences between the rates of urea hydrolysis of the main effect of temperature and the selected contrasts between urea level and $\mathrm{pH}$ combinations of the reduced model. The higher temperature showed faster rates of urea hydrolysis compared with the lower temperature $(P<0.0001)$. This effect of tem- 
perature is supported by previous observations (Muck, 1982).

Because the initial urea level and $\mathrm{pH}$ interaction was statistically different than zero (at the 0.05 significance level), 18 contrasts were determined comparing hydrolysis rates for the initial urea level within $\mathrm{pH}$ levels and vice versa (Figure 2). At the intermediate urea concentration added (1,000 $\mathrm{mg}$ of urea-N/dL), the urea hydrolysis rate was higher for the $\mathrm{pH} 6$ treatment than for the $\mathrm{pH} 8$ treatment $(P=0.002)$. The finding of $\mathrm{pH}$ 6 showed that the highest hydrolysis rate was slightly lower than that found by Muck (1982), which was between $\mathrm{pH} 6.8$ and 7.6 and lower by $2 \mathrm{pH}$ units compared with a more recent study (Dai and Karring, 2014; pH 8 ). These differences could be due to the experimental conditions, such as temperature and $\mathrm{pH}$, between studies and also because of the shift of $\mathrm{pH}$ in the current study toward a median $\mathrm{pH}$ across all treatments to $\mathrm{pH}$ 8.25. The current experiment did not buffer the slurries so $\mathrm{pH}$ changes were possible from initial to final measurements. All other contrasts comparing hydrolysis rates of treatments with varying $\mathrm{pH}$, within initial urea concentration levels, were not significantly different than zero (Figure 2). The rate of urea hydrolysis was higher for the intermediate initial urea level $(1,000 \mathrm{mg}$ of urea- $\mathrm{N} / \mathrm{dL}$ ) than the treatment of higher initial urea level (1,500 mg of urea-N/dL) across $\mathrm{pH}$. In particular, the rate of urea hydrolysis at the intermediate initial urea level was greater than that at the highest initial urea at $\mathrm{pH} 6(P<0.001)$, $\mathrm{pH} 7(P=0.049)$, and $\mathrm{pH}$
$8(P=0.014)$. These differences imply that urease activity may have been limiting as the urea concentration levels increased in the final slurry from 500 to 750 $\mathrm{mg}$ of urea-N/dL. The other contrasts describing the change in urea hydrolysis rate with varying initial urea concentration within $\mathrm{pH}$ were not statistically different from zero. As mentioned previously, the final median $\mathrm{pH}$ was 8.25 across all treatments. All 2-way and 3-way interactions were significant in the linear model describing treatment effects on the final $\mathrm{pH}$, making any meaningful comparisons difficult. Essentially, the $\mathrm{pH}$ in all treatment combinations shifted toward 8.25 with a first quartile of 7.84 and the third quartile of 8.68.

The TAN linear model only had significant main effects for temperature and urea. The $\mathrm{pH}$ main effect and all interactions were not significant. The estimated TAN marginal means, with associated standard errors in parentheses, for the urea initial levels were 186 (5.20), 331 (5.02), and 468 (4.87) $\mathrm{mg}$ of $\mathrm{N} / \mathrm{dL}$ for low, medium, and high initial urea concentration levels, respectively. If no $\mathrm{NH}_{3}$ were emitted, these levels, assuming all urea was hydrolyzed, should be 250,500 , and $750 \mathrm{mg}$ of N/ $\mathrm{dL}$. This implies that about 26,34, and $38 \%$ of the urea-N hydrolyzed was emitted for the low, medium, and high urea concentration levels. The reason for the low levels of emission could be because of $\mathrm{pH}$, surface area, or air flow. Future studies should measure these emissions to ensure mass balance of the N. As expected, the TAN levels were significantly higher for high temperature compared with low temperature. In particular,

Table 1. Predicted urea hydrolysis rates $\left(\phi_{2}, / \mathrm{h}\right)$ and associated standard errors (SE) using the exponential model of urea hydrolysis over time ${ }^{1}$

\begin{tabular}{|c|c|c|c|c|}
\hline $\begin{array}{l}\text { Urea level }^{2} \\
(\mathrm{mg} \text { of } \mathrm{N} / \mathrm{dL})\end{array}$ & $\mathrm{pH}$ & Temperature $\left({ }^{\circ} \mathrm{C}\right)$ & Estimate $(/ \mathrm{h})$ & SE \\
\hline \multirow[t]{6}{*}{500} & \multirow[t]{2}{*}{6} & 15 & 1.04 & 0.43 \\
\hline & & 35 & 56.01 & 29.01 \\
\hline & \multirow[t]{2}{*}{7} & 15 & 1.20 & 0.41 \\
\hline & & 35 & 21.14 & 28.29 \\
\hline & \multirow[t]{2}{*}{8} & 15 & 0.34 & 0.07 \\
\hline & & 35 & 2.43 & 1.91 \\
\hline \multirow[t]{6}{*}{1,000} & \multirow[t]{2}{*}{6} & 15 & 0.31 & 0.03 \\
\hline & & 35 & 1.02 & 0.22 \\
\hline & \multirow[t]{2}{*}{7} & 15 & 0.22 & 0.01 \\
\hline & & 35 & 1.34 & 0.30 \\
\hline & \multirow[t]{2}{*}{8} & 15 & 0.19 & 0.01 \\
\hline & & 35 & 1.09 & 0.21 \\
\hline \multirow[t]{6}{*}{1,500} & \multirow[t]{2}{*}{6} & 15 & 0.17 & 0.01 \\
\hline & & 35 & 1.26 & 0.16 \\
\hline & \multirow[t]{2}{*}{7} & 15 & 0.18 & 0.01 \\
\hline & & 35 & 1.05 & 0.14 \\
\hline & \multirow[t]{2}{*}{8} & 15 & 0.16 & 0.01 \\
\hline & & 35 & 0.73 & 0.09 \\
\hline
\end{tabular}

${ }^{1}$ Rates were dependent on $\mathrm{pH}$, temperature, and urea level and were computed using the fixed effects of the full model described in Eq. [2].

${ }^{2}$ In initial urine solution. 


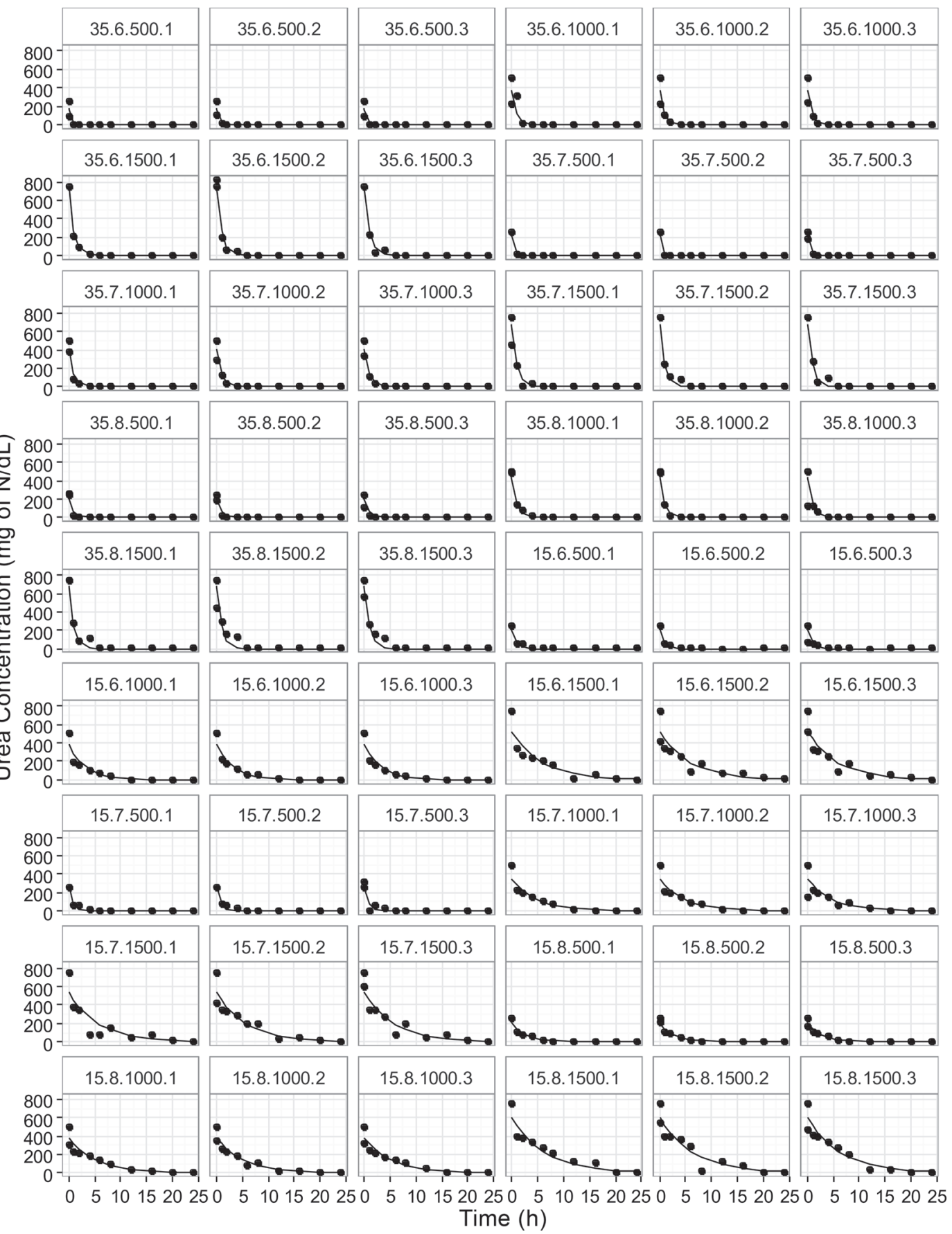

Figure 1. Urea-N concentration in slurry versus time. Dots represent the observations and the lines are the estimated fitted curve in the reduced model specific to each bottle (mixed predictions using random and fixed effects). The panel titles describe temperature, $\mathrm{pH}$, initial urea level and replicate of each slurry (i.e., 35.6.500.1 in the first panel refers to temperature $35^{\circ} \mathrm{C}, \mathrm{pH} 6$, initial urea level in urine solution of 500 $\mathrm{mg} / \mathrm{dL}$, and replicate 1 , respectively).

the estimated marginal means (and standard errors) were 311 (4.24) and 345 (3.98) $\mathrm{mg}$ of $\mathrm{N} / \mathrm{dL}$ for the $15^{\circ} \mathrm{C}$ and $35^{\circ} \mathrm{C}$ temperature treatments, respectively.

The results from this study likely represent maximum rates of urea hydrolysis because of the thorough mixing of the slurry before each sampling. In commercial dairy operations with freestall barns, considerable mixing of urine and feces on the barn floor is expected from cattle walking through the manure, although such mixing may be not as rapid or as thorough as in this study. 
The urea hydrolysis rates determined in this study for different initial urea concentration, temperature, and $\mathrm{pH}$ conditions are useful for estimating the ammoniacal $\mathrm{N}$ produced from urea. In conclusion, initial urea concentration and temperature are import factors affecting urea hydrolysis. Higher urea concentrations were associated with lower rates of urea hydrolysis. Urea hydrolysis rates were higher at $35^{\circ} \mathrm{C}$ than at $15^{\circ} \mathrm{C}$ irrespective of $\mathrm{pH}$ and initial urea levels. The effect of $\mathrm{pH}$ on urea hydrolysis was only observed between $\mathrm{pH}$ 6 and $\mathrm{pH} 8$ at the intermediate initial urea level in urine solution $(1,000 \mathrm{mg}$ of urea-N/dL). Any $\mathrm{pH}$ lower than 6 or greater than 8 may elicit a different response. The urea hydrolysis rates for all conditions tested in this study, as determined with an exponential model, demonstrated that the majority of urea is hydrolyzed within the first few hours after urine and feces mixing. The treatment combination with the fastest rate of urea hydrolysis was $35^{\circ} \mathrm{C}, \mathrm{pH} 6$, and initial urea level in urine solution of $500 \mathrm{mg}$ of $\mathrm{N} / \mathrm{dL}$. Conversely, the treatment combination with the slowest rate of urea hy- drolysis was $15^{\circ} \mathrm{C}, \mathrm{pH} 8$, and urea level in urine solution of $1,500 \mathrm{mg}$ of $\mathrm{N} / \mathrm{dL}$. The interrelationship between initial urea concentration, temperature and $\mathrm{pH}$ levels could inform management strategies aimed at reducing the amount of urea hydrolysis and subsequent ammonia levels from dairy cattle manure.

\section{ACKNOWLEDGMENTS}

The authors express their appreciation to S. J. Taylor and K. Hartman (both at University of California, Davis) for their help with the laboratory analyses and sample collection. Research was partially supported by the W. K. Kellogg Endowment, USDA National Institute of Food and Agriculture (Washington, DC) Multistate Research Project NC-2040. We gratefully acknowledge the infrastructure support of the Department of Animal Science, College of Agricultural and Environmental Sciences, and the California Agricultural Experiment Station of the University of California, Davis.

\section{$95 \%$ family-wise confidence level}

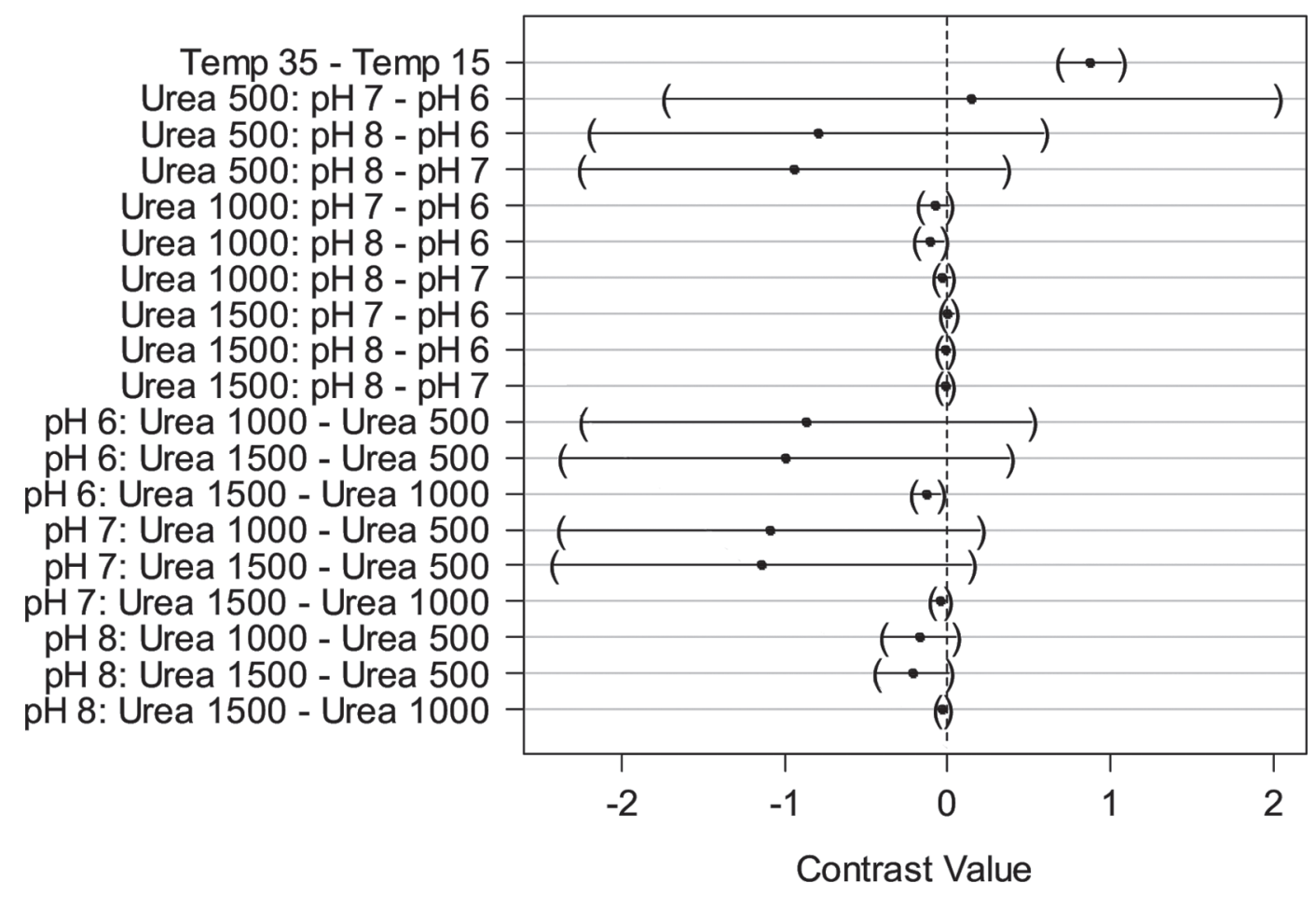

Figure 2. Multiple comparisons for the rate parameter $\left(\phi_{2}, / \mathrm{h}\right)$ of the exponential reduced model describing urea hydrolysis. The main treatments are initial urea concentration in urine solution $\left(1,500,1,000\right.$, and $500 \mathrm{mg}$ of urea-N/dL), temperature $\left(\right.$ Temp; $15^{\circ} \mathrm{C}$ and $\left.35^{\circ} \mathrm{C}\right)$, and initial $\mathrm{pH}(6,7$, and 8). Rows correspond to the comparison being made (i.e., $a-b$ is the rate of level $a$ minus the rate of level $b$, and $c: d-e$ is the rate of level $d$ minus the rate of level $e$ within the level $c$ of the other factor). Note: If interaction terms were not significantly different than zero, the main effects were compared directly. If interaction terms were significantly different than zero for any 2 factors, one factor was compared within each level of the other factor. The single-step method (Hothorn et al., 2008) was used to adjust the significance level and construct 95\% family-wise confidence intervals. 


\section{REFERENCES}

Arogo, J., R. H. Zhang, G. L. Riskowski, L. L. Christianson, and D. L. Day. 1999. Mass transfer coefficient of ammonia in liquid swine manure and aqueous solutions. J. Agric. Eng. Res. 73:77-86.

Behera, S. N., M. Sharma, V. P. Aneja, and R. Balasubramanian. 2013. Ammonia in the atmosphere: a review on emission sources, atmospheric chemistry and deposition on terrestrial bodies. Environ. Sci. Pollut. Res. Int. 20:8092-8131.

Burgos, S. A., N. M. Embertson, Y. Zhao, F. M. Mitloehner, E. J. DePeters, and J. G. Fadel. 2010. Prediction of ammonia emission from dairy cattle manure based on milk urea nitrogen: Relation of milk urea nitrogen to ammonia emissions. J. Dairy Sci. 93:2377-2386.

Burgos, S. A.. J. G. Fadel, and E. J. DePeters. 2007. Prediction of ammonia emissions from dairy cattle manure based on milk urea nitrogen: Relation of milk urea nitrogen to urine urea nitrogen excretion. J. Dairy Sci. 90:5499-5508.

Dai, X., and H. Karring. 2014. Determination and comparison of urease activity in feces and fresh manure from pig and cattle in relation to ammonia production and $\mathrm{pH}$ changes. PLoS One 9:e110402. https://doi.org/10.1371/journal.pone.0110402.

Elzing, A., and G. J. Monteny. 1997. Modeling and experimental determination of ammonia emissions rates from a scale model dairycow house. Trans. ASAE 40:721-726.
Hothorn, T., B. Frank, and P. Westfall. 2008. Simultaneous inference in general parametric models. Biom. J. 50:346-363.

Marsh, W. H., B. Fingerhut, and E. Kirch. 1957. Determination of urea nitrogen with diacetyl method and an automatic dialyzer apparatus. Am. J. Clin. Pathol. 28:681-688.

McCubbin, D. R., B. J. Apelberg, S. Roe, and F. Divita. 2002. Livestock ammonia management and particulate-related health benefits. Environ. Sci. Technol. 36:1141-1146.

Monteny, G. J., and J. W. Erisman. 1998. Ammonia emissions from dairy cow buildings: A review of measurement techniques, influencing factors and possibilities for reduction. Neth. J. Agric. Sci $46: 225-247$.

Muck, R. E. 1982. Urease activity in bovine feces. J. Dairy Sci. 65:2157-2163

Noel, R. J., and L. G. Hambleton. 1976. Collaborative study of a semiautomated method for the determination of crude protein in animal feeds. J. Assoc. Off. Anal. Chem. 59:134-140.

Pinheiro, J., D. Bates, S. DebRoy, D. Sarkar, and R Core Team. 2016. nlme: Linear and nonlinear mixed effects models. $\mathrm{R}$ package version 3.1-128. http://CRAN.R-project.org/package=nlme.

Pinheiro, J., and D. M. Bates. 2000. Mixed effects models in S and SPLUS. Statistics and Computing. Springer, New York, NY. 